\title{
SOME TRIBOLOGICAL INVESTIGATIONS ON ZINC BASE ALLOY
}

\author{
Veeresha G \\ Assistant Professor, Department of Mechanical Engineering, New Horizon College of Engineering, Bangalore- \\ 560103, Karnataka, India, \\ veermech87@gmail.com
}

\begin{abstract}
ZA-27 alloys reinforced by Mn-containing intermetallic compounds were prepared and effect of Mn content on impact strength, hardness, tensile strength, volumetric wear rate and surface roughness were examined. By adding Mn, Si, $\mathrm{Cu}, \mathrm{Mg}$ into ZA-27, experimental alloys were fabricated by gravity die casting. The volume fraction and grain size of the Mn-containing intermetallic compound phases vary with the changing of Mn content. As the percentage of Mn increases the volume fraction and size of the precipitates increased. Volumetric wear rate of the reinforced ZA-27 alloys at room temperature were measured. The results show that the impact strength and hardness values are increased with increase in Mn up to 1\%. Ultimate tensile strength and Volumetric wear rate decreased with increase in Mn up to $1 \%$. But surface roughness is decreases almost with increase in the Mn content. Better tribological properties of these alloys can be achieved at a Mn content of $1 \%$.
\end{abstract}

Keywords: ZA-27, Intermetallic Compounds, Impact Strength, Hardness, Tensile Strength, Volumetric Wear Rate, Surface Roughness

\section{INTRODUCTION}

Since the Second World War, Zn-Al alloys have been successfully developed to replace lead bronzes in bearings and bushings. Compared to lead bronze, ZA alloys offer a combination of high strength, low density and low cost [1]. Zinc-Aluminum (ZA) alloys were developed since 19601970. In particular, the ZA-12 and ZA-16 families were developed by the International Lead Zinc Research Organization (ILZRO) during 1960's, while the ZA-8 and ZA-27 were developed by Noranda Co. in the late 1970's. An important aspect that makes these alloys attractive is the low energy requirement to achieve casting, due to their low melting point as compared with aluminum, brass and iron alloys [2-4]. ZA alloys have a strength comparable to aluminium casting alloys, wear-resisting properties comparable to bearing bronzes while have lower cost and properties similar to many cast irons but are easier to machine. They have been applied to many high performance parts as substitutes for cast irons and aluminium alloys, or applied to bearings and bushings as substitutes for bronzes. For bearings working under heavy load, high mechanical properties as well as good tribological properties at room and elevated temperatures are required. By means of changes in processing techniques and using modifying elements such as rare earth elements(RE), Mn, Ti, B, the mechanical properties of ZA alloys can be improved [5]. It is the aim of this work to investigate the effect of different additions of $\mathrm{Mn}$ on the micro structural and tribological properties of the ZA-27 alloy at room temperature.

\section{EXPERIMENTAL}

The chemical composition of experimental alloys in mass percent were based on the ZA-27 alloy with a slightly higher Mn content. A series of alloys with different Mn contents were prepared by gravity die casting. Chemical compositions of the experimental alloys are listed in Table 1. Melting was made in crucible furnace at $740^{\circ} \mathrm{C}$. The raw materials were melted in a graphite crucible.

The microstructure and worn surface were examined by optical microscopy. The micro-hardness was measured on a model AICTE-RPS micro-hardness tester. Impact strength was measured by an AICTE-MODROBS impact testing machine. Brinell hardness was measured by an DST-FIST hardness tester. Tensile properties were tested on a DSTSERC tensile testing machine. Volumetric wear rate was measured by a TR-201CL wear testing machine. Surface roughness was measured by a SJ-201P surftest machine.

Table 1.Chemical composition of experimental alloys (in mass percent, by wt. chemical analysis)

\begin{tabular}{|l|l|l|l|l|}
\hline $\mathrm{Mn}$ & $0.2 \%$ & $0.5 \%$ & $1 \%$ & $5 \%$ \\
\hline $\mathrm{Al}$ & $27 \%$ & $27 \%$ & $27 \%$ & $27 \%$ \\
\hline $\mathrm{Cu}$ & $2 \%$ & $2 \%$ & $2 \%$ & $2 \%$ \\
\hline $\mathrm{Si}$ & $3.5 \%$ & $3.5 \%$ & $3.5 \%$ & $3.5 \%$ \\
\hline $\mathrm{Mg}$ & $0.04 \%$ & $0.04 \%$ & $0.04 \%$ & $0.04 \%$ \\
\hline $\mathrm{Zn}$ & Balance & Balance & Balance & Balance \\
\hline
\end{tabular}




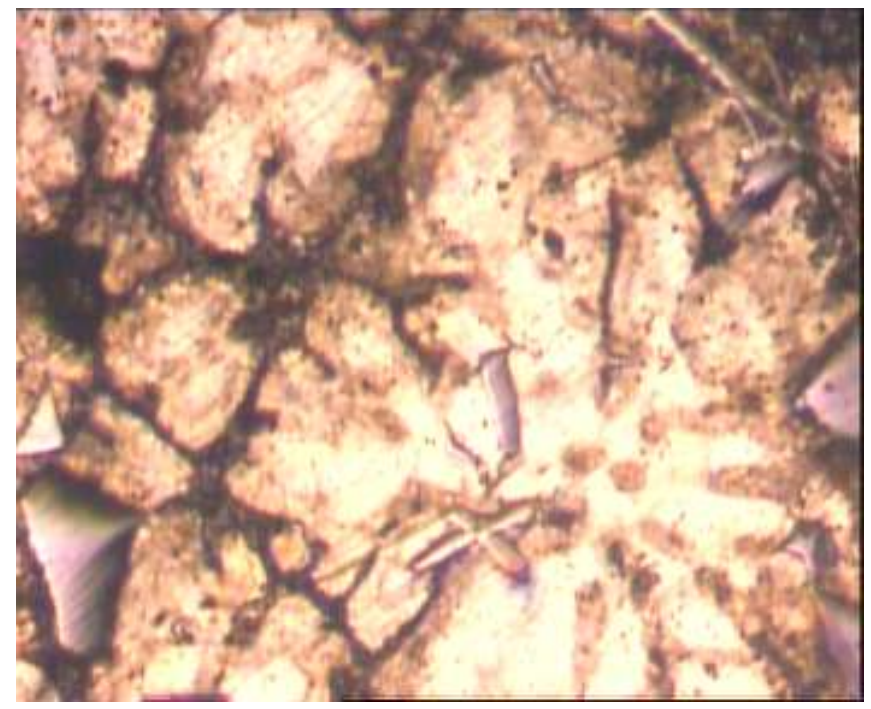

(a)

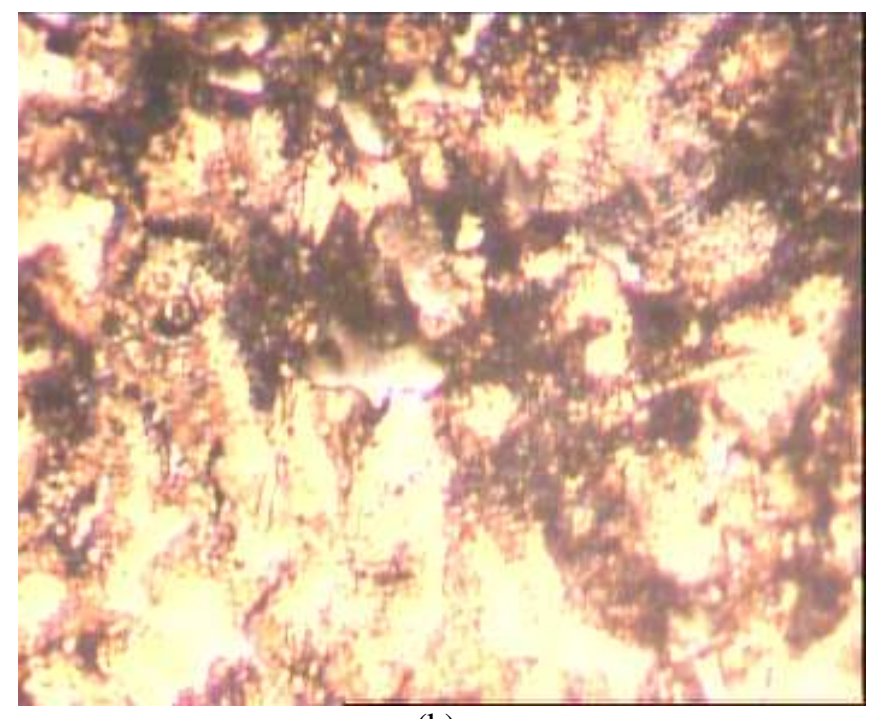

(b)

Fig.1 Microstructure of ZA-27 alloys with different wt $\%$ of $\mathrm{Mn}$ : (a) 0.2 , (b) 0.5 , (c) 1 and (d) 5

\section{RESULTS AND DISCUSSION}

\subsection{Microstructure}

The micro structural study starts with the optical microscopy. All the cast samples, after polishing have been studied using image analyzer to see the microstructure. The image analyzer photomicrographs of ZA-27 alloys are shown in fig 1.

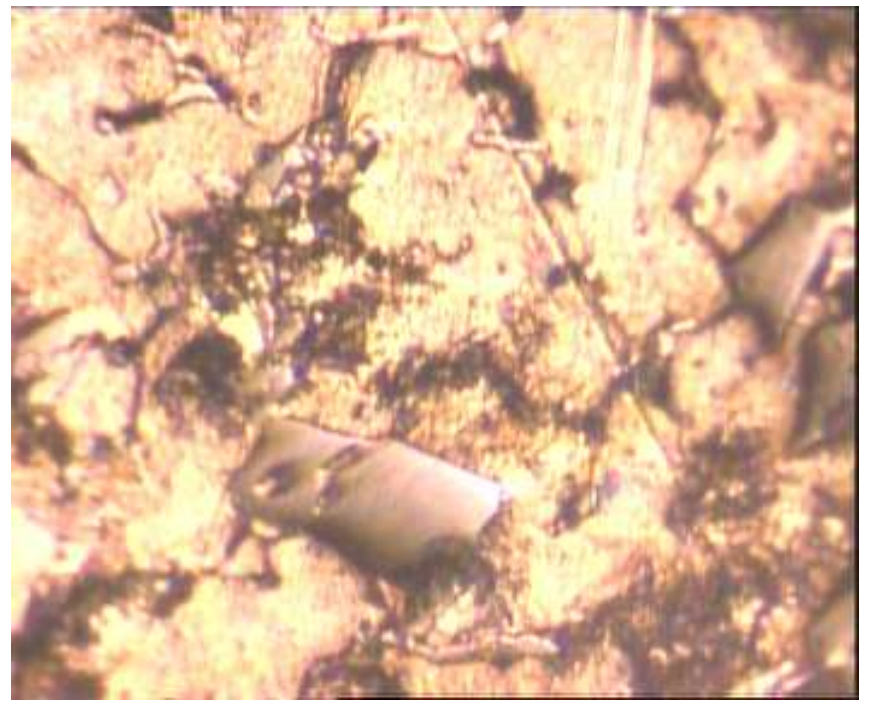

(c)

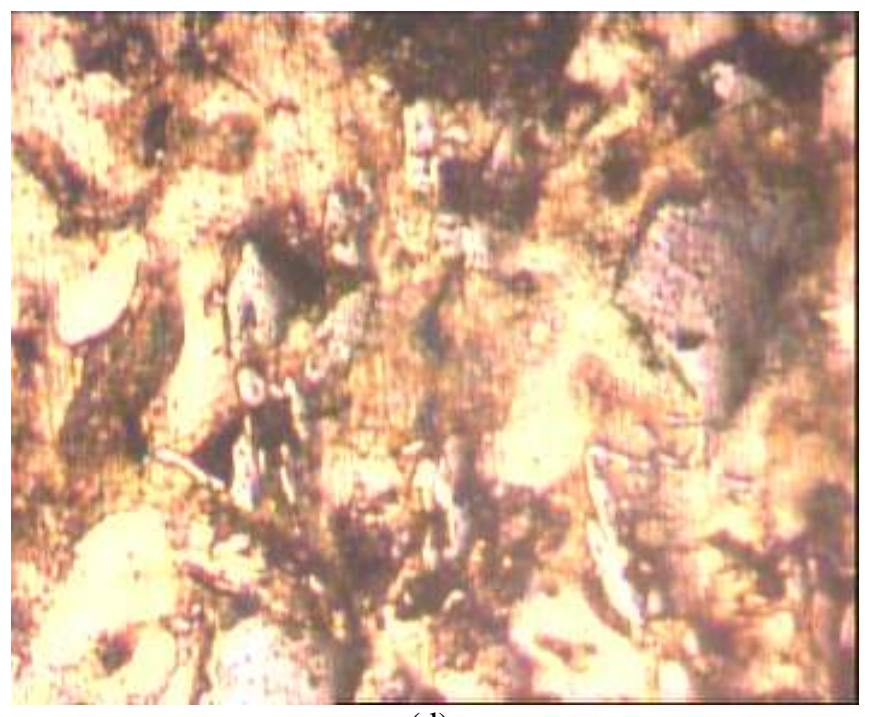

(d)

The figs show the typical microstructures of alloys ZA-27, for different manganese concentrations. It can be noticed that the number of precipitates increased with manganese content. Three different precipitate shapes were identified, globular, plate like and faceted. As the percentage of $\mathrm{Mn}$ increases the volume fraction and size of the precipitates increased.

\subsection{Impact Test}

Tough materials absorb more energy, while brittle materials tend to absorb very little energy prior to fracture. 


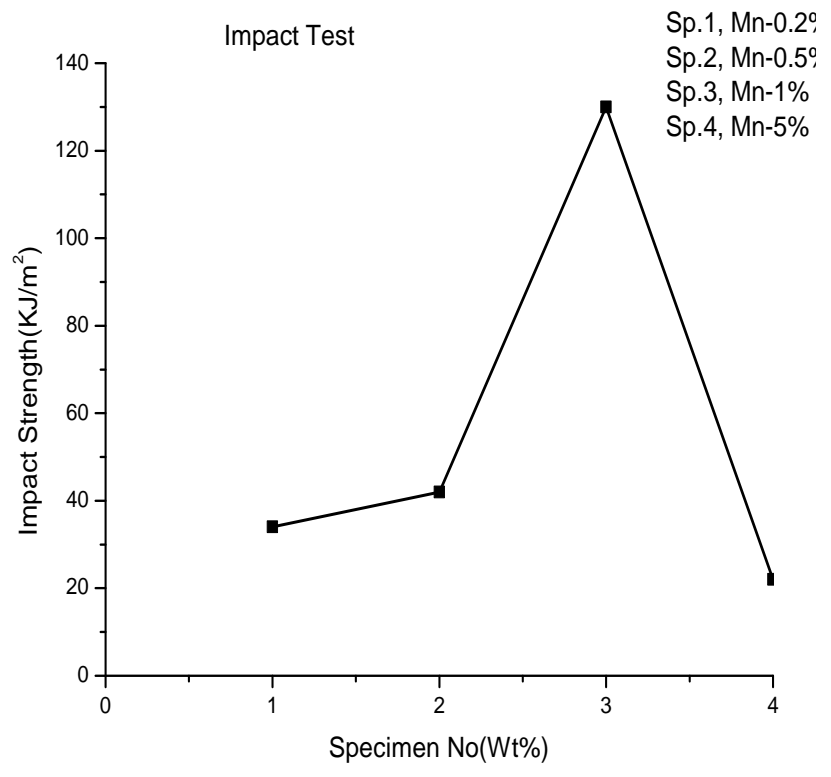

Fig.2 Effect of Mn on Impact strength

From the fig. 2 it is observed that with increase in the percentage of $\mathrm{Mn}$ the impact strength is increased and further increase in the $\mathrm{Mn} \%$ the impact strength is decreased.

With increase in the percentage of Mn hardness values will increase. As the hardness increases its corresponding toughness will decrease. Up to certain limit of the hardness toughness will not decrease more also some percentage of toughness will retain in the material. It is observed that up to increase in the Mn 1\% toughness is increased and further increase in the Mn percentage the toughness is decreased. Above $1 \%$ of $\mathrm{Mn}$ the material tends towards brittleness due to the hardness. Brittle materials will absorb less energy than the ductile material. For ZA27 alloy it is observed that $1 \%$ of Mn gives maximum toughness value.

\subsection{Hardness Test}

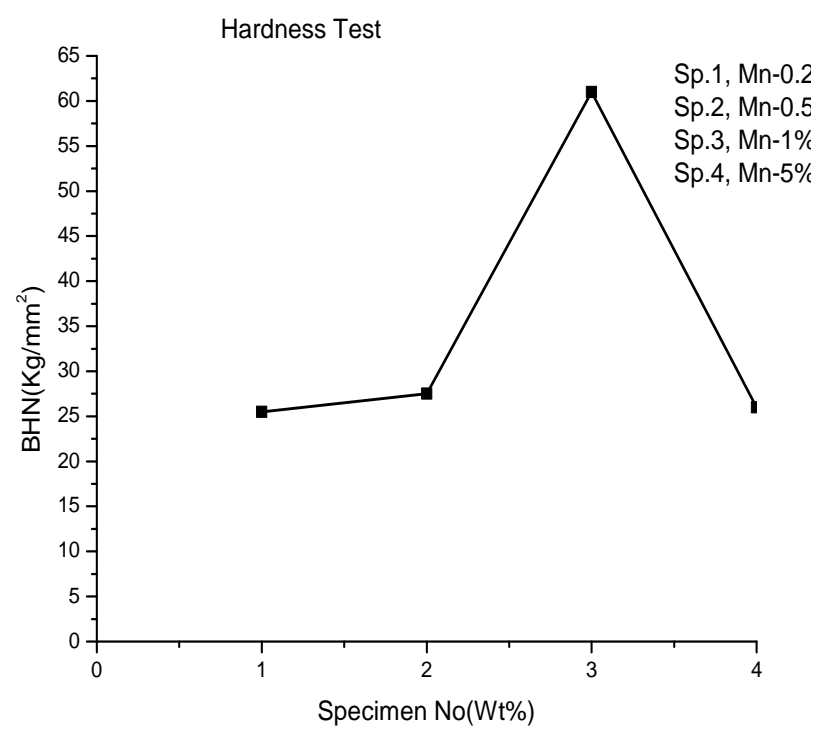

Fig.3 Effect of Mn on Hardness test
From the fig. 3 it is observed that with increase in the percentage of $\mathrm{Mn}$ the hardness is increased and further increase in the $\mathrm{Mn} \%$ the hardness is decreased. It is observed that the volume fraction and size of the hard phase in experimental alloy increase with increasing $\mathrm{Mn}$ content therefore the hardness of the alloy first increase with increase in volume fraction of hard phases then drop with the coarsening of the hard phase [5]. By adding the Mn in the ZA alloy the hardness values are increased. The hardness value of the $\mathrm{Zn}$ is $412 \mathrm{MPa}$ where as hardness value of $\mathrm{Mn}$ is $196 \mathrm{MPa}$. Initially with increase in the volume fraction of the $\mathrm{Mn}$, the hardness is increased. The increase in the hardness can be attributed to the presence of hard Al-Mn precipitates, but also to their shape, distribution and formation of the fine lamellar $\alpha+\beta$, as long as the presence of manganese is detected [6]. Initially with increase in Mn\% hardness value is increased, maintains some percentage of toughness. With further increase in $\mathrm{Mn} \%$ hardness value is decreased due to increase in brittleness at the cost of the toughness. Hence with increase in brittleness hardness value is decreased.

\subsection{Tensile Test}

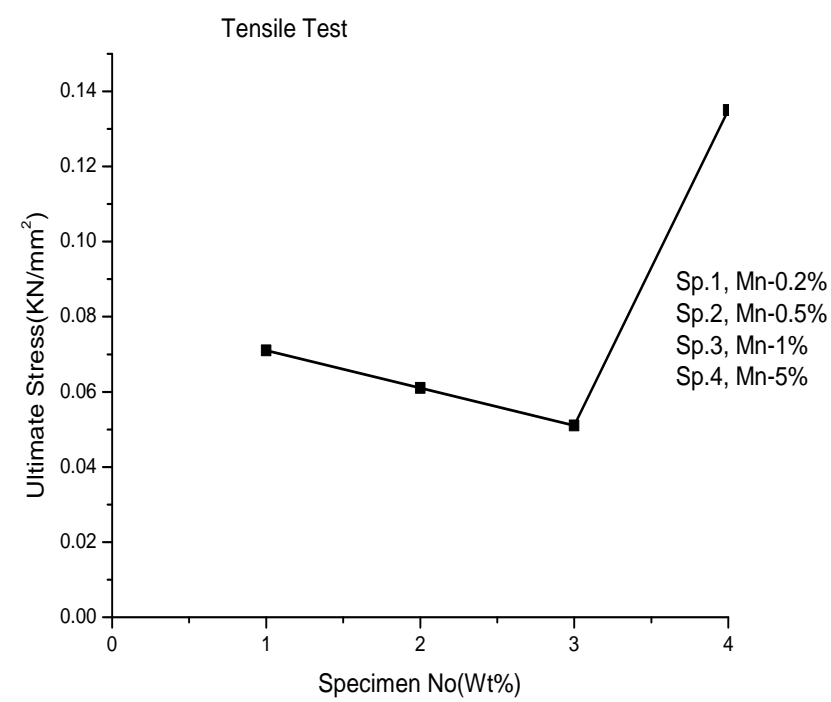

Fig.4 Effect of Mn on Ultimate stress

From the fig.4 it is observed that with increase in the percentage of $\mathrm{Mn}$ the tensile strength is decreased and further increase in the $\mathrm{Mn} \%$ the tensile strength is increased.

With increase in the Mn hardness will increased but not the detected the Mn till $1 \%$ of the Mn. Above $1 \%$ of the Mn, $\mathrm{Mn}$ is detected. Hence, above $1 \% \mathrm{Mn}$ the ultimate tensile strength is increased [6]. Actually with increase in brittleness the tensile strength should decrease but with increase in $\mathrm{Mn}$ size and volume fraction the precipitates is increased. Hence with further increase in $\mathrm{Mn}$ the tensile strength is increased. 


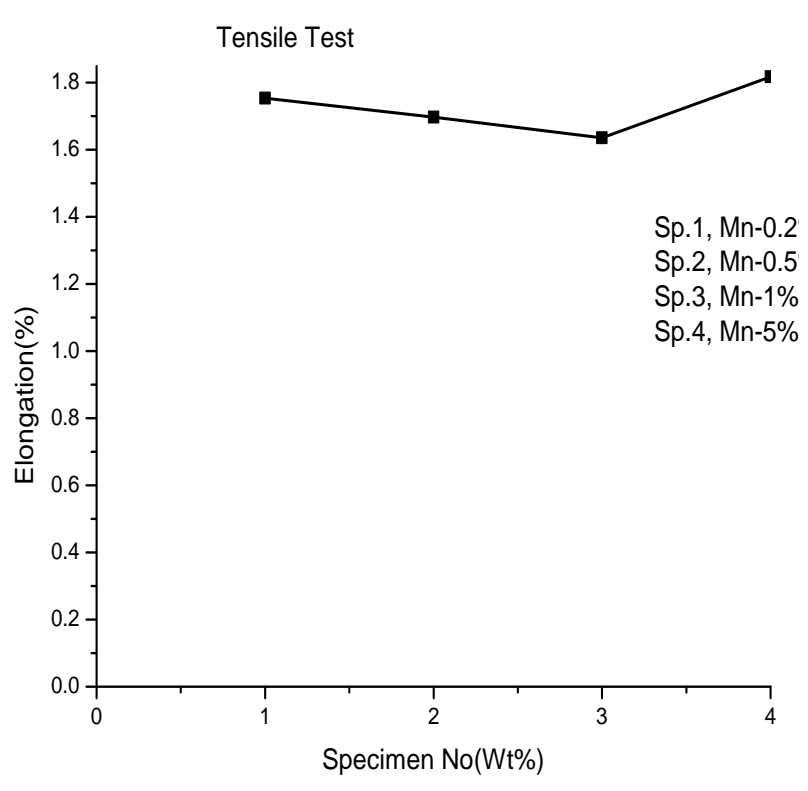

Fig.5 Effect of Mn on Elongation

From the fig.5 it is observed that with increase in the percentage of $\mathrm{Mn}$ the elongation is decreased and further increase in the $\mathrm{Mn} \%$ the elongation is increased

With increase in the Mn content hardness is increased hence elongation is decreased. With further increase in the $\mathrm{Mn}$ content hardness is decreased hence elongation is increased, due to the precipitation.

\subsection{Wear Test:}

All the composites developed were tested on the pin on disc machine. The effect of various tribological parameters load and speed was tested on each composite and compared with the wear behavior.

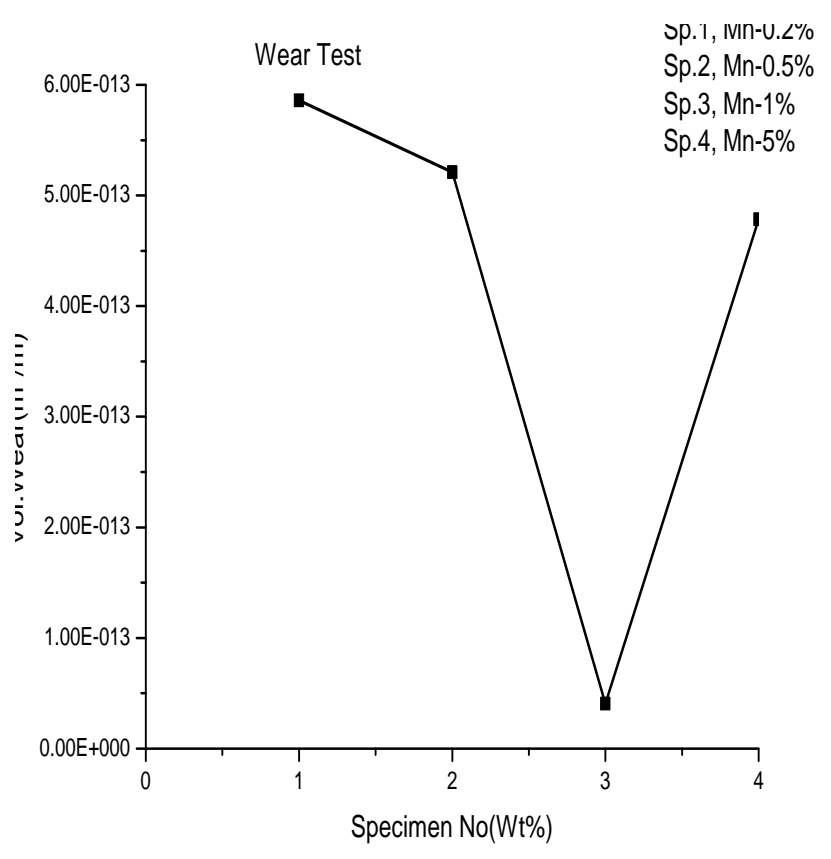

From the fig.6 it is observed that with increase in the percentage of $\mathrm{Mn}$ the volumetric wear is decreased and further increase in the $\mathrm{Mn} \%$ the volumetric wear is increased.

Volumetric wear rate is a function of normal load, sliding distance and hardness. Volume loss is inversely proportional to the hardness of the material as per Archard. i.e. $\mathrm{V}=$ $\mathrm{k} *$ Normal load $*$ sliding distance / Hardness.

With increase in the volume fraction of the Mn hardness is increase up to $1 \%$ of the $\mathrm{Mn}$, hence volumetric wear rate is decreased. With further increase in the volume fraction of the $\mathrm{Mn}$ the corresponding hardness is decreased. Hence, the corresponding volume loss is increased. Therefore the volumetric wear rate is increased, due to the increase in brittleness.

With increase in the volume fraction of the Mn, volumetric wear rate is decreased. Volumetric wear rate is inversely proportional to the hardness. Therefore with increase in the Mn volumetric wear rate is increased. With further increase in the volume fraction of the Mn hardness is decreased but volumetric wear rate is increased. Therefore the volumetric wear rate is increased due to the brittleness of the worn surface.

\subsection{Surface Roughness(Perpendicular) Test:}

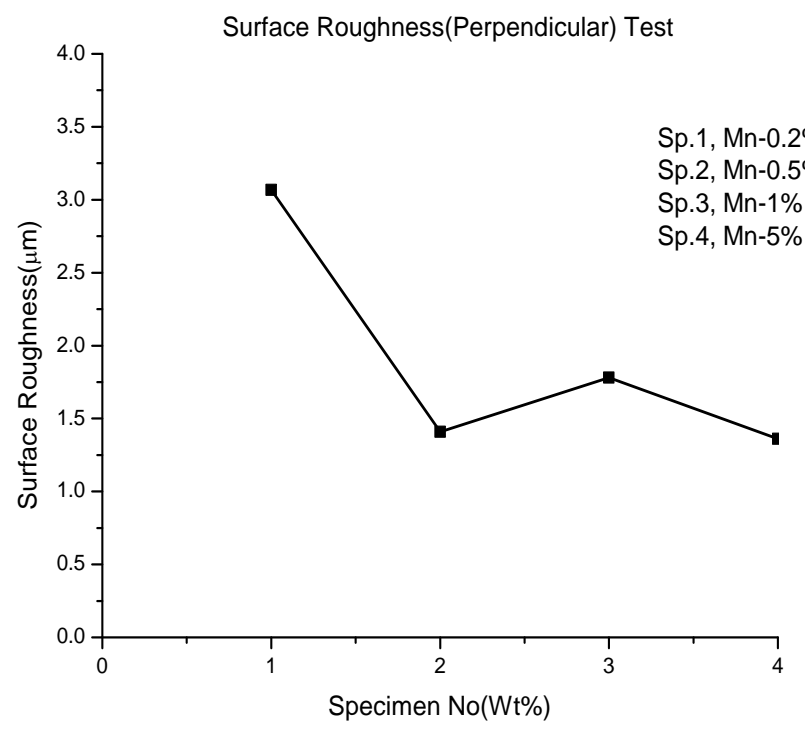

Fig.7 Effect of Mn on Surface Roughness test

From the fig.7 it is observed that with increase in the percentage of Mn the surface roughness is almost decreased. With increase in the Mn the material becomes hard and hence surface roughness is decreased. Due to hardness the worn surface wears due to shearing action of the material removal rather than tearing action.

Fig.6 Effect of Mn on Wear test 


\subsection{VPN Test:}

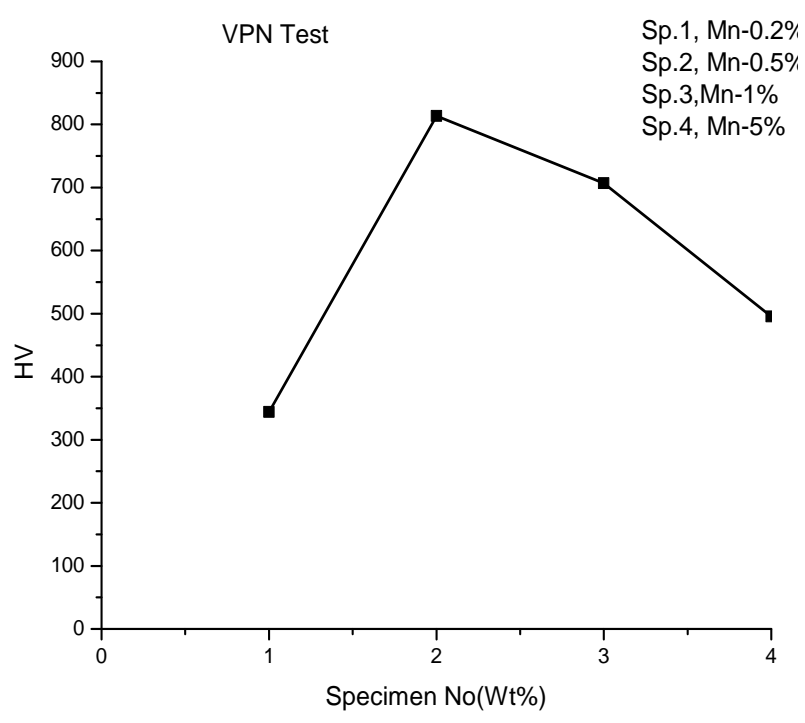

Fig.8 Effect of Mn on VPN test

From the fig. 8 it is observed that with increase in the percentage of $\mathrm{Mn}$ the hardness is increased and further increase in the Mn\% the hardness is decreased.

Initially surface hardness after wear is increased with increase in the Mn percentage. Further increase in the Mn percentage it tends towards brittleness hence, surface hardness is decreased with the increase in the percentage of the Mn.

\section{CONCLUSION}

It was found that addition of Mn over the entire range of concentrations has a useful effect on hardness, volumetric wear rate, impact strength, surface roughness and tensile strength of the alloy. Impact strength and hardness values are increased with increase in Mn up to $1 \%$ but decreased with further increase in $\mathrm{Mn}$ content. Ultimate tensile strength and volumetric wear rate decreased with increase in Mn up to $1 \%$ and increased with further increase in $\mathrm{Mn}$ content. But surface roughness decreases with increase in the Mn content. Better tribological properties of these alloys can be achieved at a Mn content of $1 \%$.

\section{REFERENCES}

[1] LONG Yan, LI Yuan-yuan, ZHANG Da-tong, QIU Cheng, CHEN Wei-ping "Sliding wear and friction behavior of ZA-27 alloy reinforced by Mn-containing intermetallic compounds". Trans. Nonferrous Met. Soc. China. Vol. 12, No. 4,Aug 2002. Pp 0775-0779

[2] R. J. BARNHURST, E. GERVAIS and F. D. BAYLES, AFS Transactions 91 (1983) 569.

[3] E. GERVAIS, R. J. BARNHURST and C. A. LOONG, J. Met. 11 (1985) 43.

[4] COMINCO Ltd. Zinc Foundry Alloys, Tech. Report. 11 (1985).

[5] LI Yuan-yuan, LONG Yan CHEN Wei-ping, ZHANG Darlong, SHAO Ming 'Effect of Mn content on microstructure and mechanical properties of modified ZA-27 alloy'. Trans. Nonferrous Met. Soc. China. Vol.12, No.6, Dec.2002. pp.1091 - 1094

[6] C. DOMINGUEZ, M. V. MORENO LOPEZ, D. RIOSJARA "The influence of manganese on the microstructure and the strength of a ZA-27 alloy". Journal of materials science. 37, 2002. Pp.5123-5127 